\title{
Functional Outcome of Supracondylar Fracture Femur Treated By Locked Compression Plating - A Prospective Study
}

\author{
Authors \\ Dr Biju $\mathbf{S}^{\mathbf{1}}$, Dr Sabarisree $\mathbf{M}^{\mathbf{2}}$ \\ ${ }^{1}$ Assistant Professor in Orthopaedics, Govt Medical College, Thiruvananthapuram \\ ${ }^{2}$ Associate Professor (CAP) in Orthopaedics, Govt Medical College, Thiruvananthapuram
}

\begin{abstract}
Introduction: Supracondylar fractures of distal femur often are unstable and comminuted and tend to occur in elderly or multiply-injured patients. The incidence is highest in women older than 60 years and in men over 20 years age. Because of the proximity of these fractures to the knee joint, regaining full knee motion and function may be difficult. The incidence of mal union, nonunion, and infection are relatively high in many reported studies This study is aimed to assess the functional outcome of supracondylar fracture femur treated by locked compression plate in an age group of 20-90 years.

Materials and Methods: This is a prospective study of 21 patients who underwent this procedure in Govt Medical College Hospital Thiruvananthapuram between 2008-2010. Majority of the patients were less than 60 years of age. Males constituted majority of the study subjects and Road traffic Accidents were found to be the major mode of injury. Results were evaluated LEM score and modified Knee score.

Results: All the cases were operated within 24 hours following fracture. Among the 21 patients, $16(76.19 \%)$ had a LEM score of $>81$ and $14(66.6 \%)$ had good to excellent knee score.

Conclusion: Open reduction and internal fixation with Locked Compression Plating offers anatomical reduction of the intraarticular fragments, stable and rigid fixation, better soft tissue and bone healing. With regard to functional outcome, this procedure offers good results to the young and elderly who sustain supracondylar fracture femur.
\end{abstract}

\section{Introduction}

Supracondylar fractures of the distal femur historically have been difficult to treat. These fractures often are unstable and comminuted and tend to occur in elderly or multiply-injured patients. The incidence is highest in women older than 60 years and in men over 20 years age. Because of the proximity of these fractures to the knee joint, regaining full knee motion and function may be difficult. The incidence of malunion, nonunion, and infection are relatively high in many reported studies ${ }^{1}$.
There are various treatment options available to treat this fracture including conventional plaster cast for those patient medically not fit for surgical procedures and surgically by external fixators, retrograde femoral interlocking intra medullary nailing, dynamic condylar screw with side plating, condylar buttress plating and locked compression plating.

In the past three decades with the improvements in surgical techniques and implants popularized by the AO group there has been an unmistakable trend towards surgical management of these 
fractures. It is now recognized by most orthopaedic surgeons that distal femoral fractures are best treated with reduction and surgical stabilization ${ }^{2}$.

The basic principle of any fracture treatment is to offer a rigid fixation following a stable reduction until the union is sound with restoration of full physiological function of joints and muscles to its maximum possible extent. Despite the advances in techniques and improvement in surgical implants, treatment of fractures of the distal femur remains a challenge in many situations. Thorough debridement, adequate soft tissue coverage, anatomical reduction of articular surface, stable internal fixation, restoration of limb alignment and early mobilization have been shown to be an effective way of managing these type of fractures.

For retrograde femoral nailing to achieve adequate fracture stabilization, the fracture should be at least $6 \mathrm{~cm}$ from the joint line to achieve distal locking with two transverse screws or a screw and a spiral blade. In contrast, more distal fixation can be achieved with plates, or locked fixators. For example the distal most screws in a LISS plate, or a condylar plate, may be subchondral ${ }^{3}$.

The distal-most fixation for various implants are:

- LISS plate: subchondral

- Condylar plate: subchondral

- $95^{\circ}$ angled blade plate: $1.5-2 \mathrm{~cm}$

- $95^{\circ}$ dynamic condylar screws: $2 \mathrm{~cm}$

- Retrograde intramedullary nail: $6 \mathrm{~cm}$ (for 2 locking screws, or one locking screw and a spiral blade)

Locked compression plating received increased attention for treating the distal femur fractures now a days because these fractures mainly occurs in elderly population with osteoporotic bone. It provides better contour to the distal femur, anatomical reduction and stable fixation, which is most important for the functional outcome. Another advantage of LCP is that it minimizes the incidence of leg length discrepancies and rotational and angulations deformities ${ }^{4}$.

In our institution the most common method of intervention for supracondylar fracture femur followed now a days is LISS plating with a few modifications. The classical LISS plating procedure is minimally invasive but in our institution we follow the open reduction and internal fixation (ORIF). And the functional outcome of this procedure has never been evaluated properly. We decided to study the functional outcome of this procedure followed in our institute (Dept. Orthopaedics $\mathrm{MCH}$ Thiruvananthapuram)

\section{Objectives}

1. To assess the functional outcome of supracondylar fracture femur treated by locked compression plate in an age group of 20-90 years.

2. To analyse the age distribution, sex distribution, mode of injury, rate of union and its complication

\section{Materials and Methods \\ Operative Technique}

\section{Approach and Position of the Patient}

The posterolateral approach can expose the entire length of the femur. Because it follows the lateral intermuscular septum, it does not interfere with the quadriceps muscle. Although other lateral approaches involve splitting the vastus lateralis or vastus intermedius muscles, the functional results of the posterolateral approach do not differ significantly from those of other approaches, probably because the vastus lateralis originates partly from the lateral intermuscular septum. As a result, surgery still involves detaching a part of the muscle's origin and does not use a true intermuscular plane. This septum overlies the middle of the shaft at its distal end. The posterolateral approach is therefore ideal for exposure of the distal one third of the femur. The more proximal the approach, the greater the bulk of the vastus lateralis that will need to be retracted anteriorly. The uses of the posterolateral approach include open reduction and plating of femoral fractures, especially supracondylar fractures. 


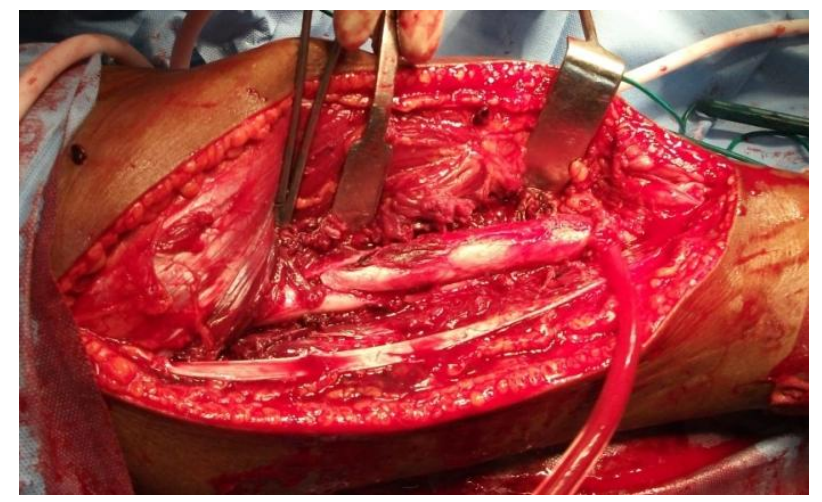

Place the patient supine on the operating table with a sandbag beneath the buttock on the affected side to elevate the buttock and to rotate the leg internally, bringing the posterolateral surface of the thigh clear of the table. Palpate the lateral femoral epicondyle on the lateral surface of the knee joint. The epicondyle actually is a flare of the condyle. Moving superiorly, note that the femur cannot be palpated above the epicondyle.

Make a longitudinal incision on the posterolateral aspect of the thigh. Base the distal part of the incision on the lateral femoral epicondyle and continue proximally along the posterior part of the femoral shaft. The exact length of the incision depends on the surgery to be performed. The approach exploits the plane between the vastus lateralis muscle (which is supplied by the femoral nerve) and the lateral intermuscular septum, which covers the hamstring muscles (which are supplied by the sciatic nerve; Incise the deep fascia of the thigh in line with its fibers and the skin incision. Identify the vastus lateralis under the fascia lata. Follow the muscle posteriorly to the lateral intermuscular septum. Then, reflect the muscle anteriorly, dissecting between muscle and septum. Numerous branches of the perforating arteries cross this septum to supply the muscle; they must be ligated or coagulated Continue the dissection, following the plane between the lateral intermuscular septum and the vastus lateralis muscle, detaching those parts of the vastus lateralis that arise from the septum until the femur is reached at the linea aspera. Incise the periosteum longitudinally at this point and strip off the muscles that cover the femur, using subperiosteal dissection. Detaching muscles from the linea aspera itself usually has to be done by sharp dissection.

It is very easy to open up the plane between the vastus lateralis muscle and the lateral intermuscular septum in the distal third of the femur. To aid in this process, place a Homan or Bennett retractor over the anterior aspect of the femoral shaft, lifting the vastus lateralis forward. A retractor placed on the lateral intermuscular septum will help open up the gap and facilitate proximal dissection.

The perforating arteries (which are branches of the profunda femoris artery) pierce the lateral intermuscular septum to supply the vastus lateralis muscle. They must be ligated or coagulated one by one as the dissection progresses. If they are torn flush with the lateral intermuscular septum, they may begin to bleed out of control as they retract behind it.

The superior lateral geniculate artery and vein cross over the lateral surface of the femur at the top of the femoral condyles. These vessels will need to be ligated for exposure to the bone.

The approach can be extended easily into a lateral parapatellar approach to the knee joint. This allows accurate visualization of the entire distal end of the femur. This extension is used to allow reduction and fixation of intraarticular fractures of the distal femur.

\section{Instruments and Implants}

The plate used for fixation of the fracture was LISS plate. This may be inserted using an open approach to the metaphysis/diaphysis fixation ${ }^{5}$. The screws used to fix the plate with the bone are the self tapping cortical and cancellous screws $5 \mathrm{~mm}$ for diaphysis and metaphysis respectively. Additional instruments required to fix the fracture include drill sleeve, drill bit and drill.

\section{Complications}

1. Infection: Open fractures require meticulous debridement and copious irrigation along with intravenous antibiotics ${ }^{6}$. Open injuries contiguous with the knee necessitate formal irrigation and debridement to prevent knee sepsis. Postoperative 
infection can be best prevented by adequate antibiotics.

2. Malunion: This is usually results from unstable fixation. Varus is the most common deformity. Malunion with the articular surface in extension may result in relative hyperextension of the knee, whereas Malunion in flexion may result in functional loss of full extension. Malunion resulting in functional disability may be addressed with osteotomy ${ }^{7}$.

3. Nonunion: This is infrequent because of the rich vascular supply to this region and the predominance of cancellous bone ${ }^{8}$.

4. Fixation failure: This is usually result of one of the following: poor bone stock, fracture pattern comminution, patient non compliance with postoperative care, or inadequate surgical planning and execution ${ }^{9}$.

5. Loss of knee motion: This is the most common complication as a result of scarring, quadriceps damage, or articular disruption during injury. If significant, it may require lysis of adhesions or quadricepsplasty for restoration of the knee joint motion. It is best prevented by early range of motion and adequate pain control ${ }^{10}$.

6. Post- traumatic osteoarthritis: This may result as a failure to restore articular congruity, especially in younger patients. It also may reflect chondral injury at the time of trauma ${ }^{11}$.

\section{Patients and Methods}

\subsection{Study design}

Prospective case series study

\subsection{Study setting}

Department of orthopaedics Govt Medical College Hospital Thiruvananthapuram.

\subsection{Study period}

Oct. 2008- Dec.2010

\subsection{Study subjects}

Patients admitted with supracondylar fracture femur belonging to AO/OTA type A1, A2, A3 and Intra articular $\mathrm{C} 1$ and $\mathrm{C} 2$.

\subsection{Inclusion criteria}

All supracondylar fracture (closed and compound) fixed within 24 hours with Locked Compression Plating.

\subsection{Exclusion criteria}

1. Pathological fractures.

2. Multiple fractures involving the same limb.

3. Periprosthetic fractures.

4. Existing deformity of the same limb.

\subsection{Sample size}

The sample size of the case series study was 21 .

\subsection{Sampling technique}

All patients admitted in Orthopaedics Department $\mathrm{MCH}, \mathrm{TVM}$ fulfilling the criteria during the study period were included in the study.

3.9 Method of data collection- tools, methods Initially at the casualty, detailed history, clinical examination, trauma assessment and resuscitation was carried out. Fractures were splinted Thomas splint and wound if any was cleaned with sterile gauze. Tetanus prophylaxis was given and intravenous antibiotics (Crystalline Pencillin, Cefuroxime, Metronidazole) started at the earliest (if needed). At the casualty, life threatening injuries were evaluated and treated as early as possible.

After which the patient was prepared for the surgery with all pre operative investigations. Primary fixation was done only if all circumstances were favourable.

After surgery wound inspection was carried out on $3^{\text {nd }}, 5^{\text {th }}, 8^{\text {th }}$, and $10^{\text {th }}$ post operative days and clinical signs of infection (fever, putrid smell, purulent discharge, local signs of inflammation, localised collection) were looked for. In the event of infection, a culture swab was taken from the wound and followed up for infective organism. Antibiotics were changed according to the culture sensitivity report. If there was no infection, intravenous antibiotics were stopped on $5^{\text {th }}$ day and switched over to oral antibiotics for one more week. Suture removal was done on the $10^{\text {th }}$ post operative day and patient were discharged.

At every visit, clinical as well as radiological evaluation of the fracture union was assessed. Any superficial or deep infection was noted. Functional evaluation of the knee joint also carried out.

Fracture union is defined as full painless weight bearing with callus formation at least three cortices on standard AP and lateral radiographs. 
Non union is defined as no progression of fracture healing over a three month period extending beyond six months. Delayed union defined as slow progression of fracture healing extending 4 months or beyond. For all practical purpose all fractures that did not heal by 6 months were taken as delayed union. Non union signified a fracture that would not heal without some further intervention.

Angular fracture alignment was measured radiographically; rotational and axial alignment were measured clinically. Malalignment is defined as at least either of 10 degree angulation, 15 degree malrotation or $2 \mathrm{~cm}$ length discrepancy.

\subsection{Study variables}

\subsubsection{Independent variables}
1. Age
2. Sex
3. Mode of injury
4. Side of injury
5. Classification according to AO/OTA type
6. Associated systemic injuries
7. Associated other bone and joint injuries

8. Immediate complication

9. Other surgical interventions

10. Wound infection

11. Partial weight bearing

12. Full weight bearing

13. Secondary procedures

14. Fracture union

15. Complication

\subsubsection{Outcome variable}

1. Activity of daily living assessed by LEM score

2. Functional evaluation based on modified Knee score

Table 1: Abbreviated Lower Extremity measure (LEM) ${ }^{12}$

\begin{tabular}{|l|l|l|l|l|l|}
\hline Activity & \multicolumn{3}{|c|}{ Level of Difficulty } \\
\hline & $\begin{array}{c}\text { Not } \\
\text { possible } \\
1\end{array}$ & $\begin{array}{c}\text { Extreme } \\
\text { Difficulty } \\
2\end{array}$ & $\begin{array}{c}\text { Moderate } \\
\text { Difficulty } \\
3\end{array}$ & $\begin{array}{c}\text { Mild } \\
\text { Difficulty } \\
4\end{array}$ & $\begin{array}{c}\text { No } \\
\text { difficulty } \\
5\end{array}$ \\
\hline 1. Independent walking & & & & & \\
\hline 2. Walking upstairs and downstairs & & & & & \\
\hline 3. Squating & & & & & \\
\hline 4. Sitting cross-legged & & & & & \\
\hline $\begin{array}{l}\text { 5. Ability to get up from low chair } \\
\text { or bed }\end{array}$ & & & & & \\
\hline 6. Putting on a pair of pants & & & & & \\
\hline $\begin{array}{l}\text { 7. Putting on a pair of shoes or } \\
\text { similar footwear }\end{array}$ & & & & & \\
\hline 8. Looking after personal needs & & & & & \\
\hline $\begin{array}{l}\text { 9. Using usual number of hours } \\
\text { for daily activities }\end{array}$ & & & & & \\
\hline $\begin{array}{l}\text { 10.Completing usual daily } \\
\text { activities }\end{array}$ & & & & & \\
\hline
\end{tabular}


Table 2. Functional Evaluation Scale based modified knee score

\begin{tabular}{|c|c|c|}
\hline Function & Result & Points \\
\hline \multicolumn{3}{|l|}{ Range of motion (degree) } \\
\hline \multicolumn{3}{|l|}{ Flexion } \\
\hline$>125$ & Excellent & 6 \\
\hline $100-124$ & Good & 4 \\
\hline $90-99$ & Fair & 2 \\
\hline$<90$ & poor & 0 \\
\hline \multicolumn{3}{|l|}{ Loss of extension } \\
\hline o & Excellent & 3 \\
\hline$<5$ & Good & 2 \\
\hline $6-10$ & Fair & 1 \\
\hline$>10$ & Poor & 0 \\
\hline \multicolumn{3}{|l|}{ Deformation } \\
\hline \multicolumn{3}{|l|}{ Angulation (degree) } \\
\hline 0 & & 3 \\
\hline$<10$ & Good & 2 \\
\hline $10-15$ & Fair & 1 \\
\hline$>15$ & Poor & 0 \\
\hline \multicolumn{3}{|l|}{ Shortening $(\mathrm{cm})$} \\
\hline 0 & Excellent & 3 \\
\hline$<1.5$ & Good & 2 \\
\hline $1.5-2.5$ & Fair & 1 \\
\hline$>2.5$ & Poor & 0 \\
\hline \multicolumn{3}{|l|}{ Pain } \\
\hline None & Excellent & 10 \\
\hline $\begin{array}{l}\text { Occasional or with changes in } \\
\text { weather or both }\end{array}$ & Good & 7 \\
\hline With fatigue & Fair & 5 \\
\hline Constant & Poor & 0 \\
\hline \multicolumn{3}{|l|}{ Walking ability } \\
\hline Unrestricted & Excellent & 6 \\
\hline$>30$ min. to $<60 \mathrm{~min}$. & Good & 4 \\
\hline$<30$ minutes & Fair & 2 \\
\hline $\begin{array}{l}\text { Walks at home, confined to } \\
\text { wheelchair, or is bedridden }\end{array}$ & Poor & 0 \\
\hline \multicolumn{3}{|l|}{ Stair climbing } \\
\hline No limitation & Excellent & 3 \\
\hline Holds rail & Good & 2 \\
\hline One stair at a time & Fair & 1 \\
\hline Elevator only & Poor & 0 \\
\hline \multicolumn{3}{|l|}{ Return to work(A or B) } \\
\hline \multicolumn{3}{|l|}{ A. Employed before injury } \\
\hline Returned to pre injury job & Excellent & 6 \\
\hline $\begin{array}{l}\text { Returned to pre injury job with } \\
\text { difficulty }\end{array}$ & Good & 4 \\
\hline Altered fulltime job & Fair & 2 \\
\hline Par time job or un employed & poor & 0 \\
\hline \multicolumn{3}{|l|}{ B. Retired before injury } \\
\hline Retuned to pre injury life style & Excellent & 6 \\
\hline Needs occasional help & Good & 4 \\
\hline $\begin{array}{l}\text { Needs assistance at home with } \\
\text { activities of daily living }\end{array}$ & Fair & 2 \\
\hline $\begin{array}{l}\text { Moved in with family or nursing } \\
\text { home }\end{array}$ & Poor & 0 \\
\hline
\end{tabular}

\section{Statistical analysis}

Descriptive statistical analysis has been carried out in the present study. Results on continuous measurements are presented on Mean value (MinMax) and results on categorical measurements are presented in Number (\%). The analysis was carried out using SPSS Version16. Out of 22 study subjects one case was excluded for final evaluation because of head injury which will take longer period of rehabilitation.

\subsection{Ethical considerations}

Clearance was obtained from Research committee and Ethical committee of Medical College Thiruvananthapuram.

Written informed consent was obtained from the participants prior to data collection.

\section{Results}

\section{Personal Background of Sample patients}

Table 1: Percentage distribution of the sample according to age

\begin{tabular}{|l|c|c|}
\hline Age & Number & Percent \\
\hline 20-39 years & 08 & $38 \%$ \\
\hline 40-59 years & 06 & $29 \%$ \\
\hline 60-90 years & 07 & $33 \%$ \\
\hline Mean Age & \multicolumn{2}{|c|}{47.85} \\
\hline
\end{tabular}

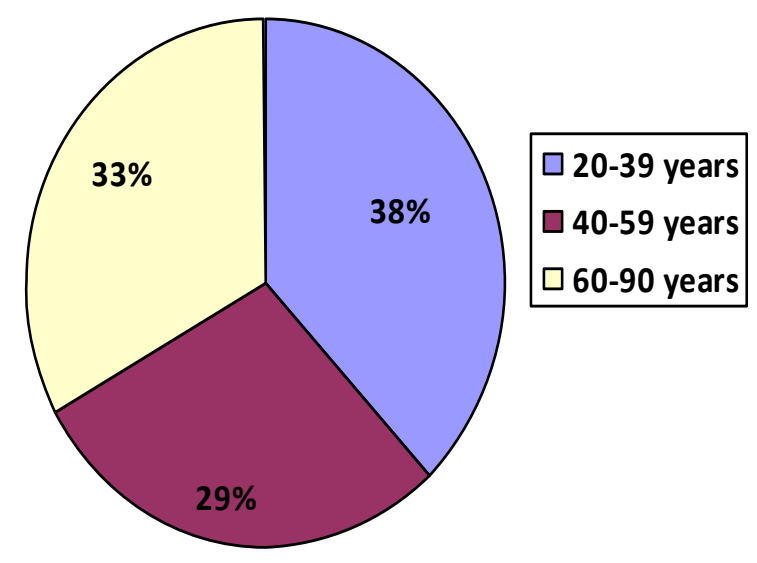

Fig. 1: Percentage distribution of the sample according to age

Table 2: Percentage distribution of the sample according to sex

\begin{tabular}{|l|c|c|}
\hline Sex & Number & Percent \\
\hline Male & 13 & $62 \%$ \\
\hline Female & 8 & $38 \%$ \\
\hline
\end{tabular}




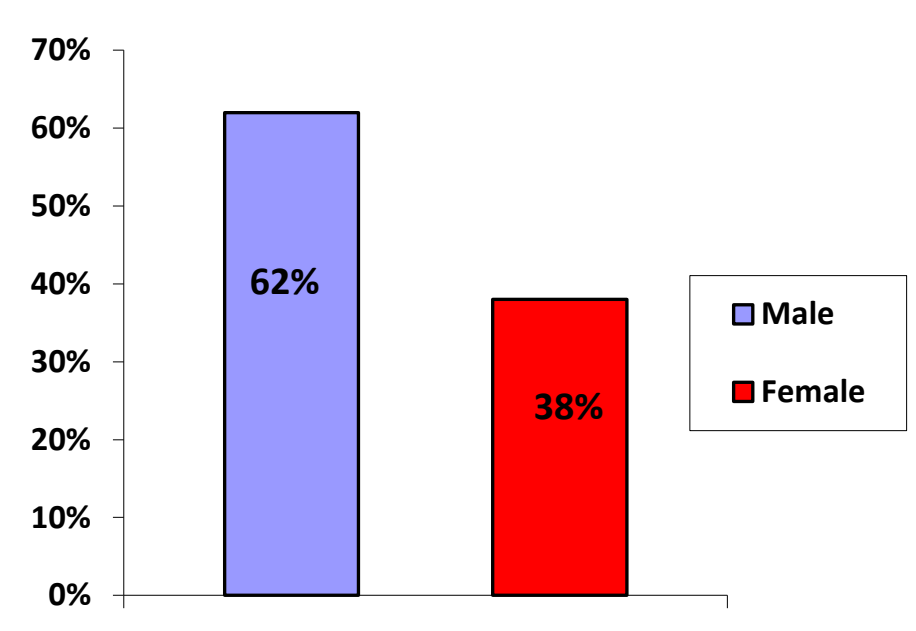

Fig. 2: percentage distribution of the sample according to sex

\section{Fracture Characteristics}

Table 3: Percentage distribution sample according to mode of injury

\begin{tabular}{|l|c|c|}
\hline Mode of injury & Number & Percent \\
\hline Road traffic accident(RTA) & 17 & $81 \%$ \\
\hline Assault & 2 & $9.5 \%$ \\
\hline Fall from height(FF Height) & 2 & $9.5 \%$ \\
\hline
\end{tabular}

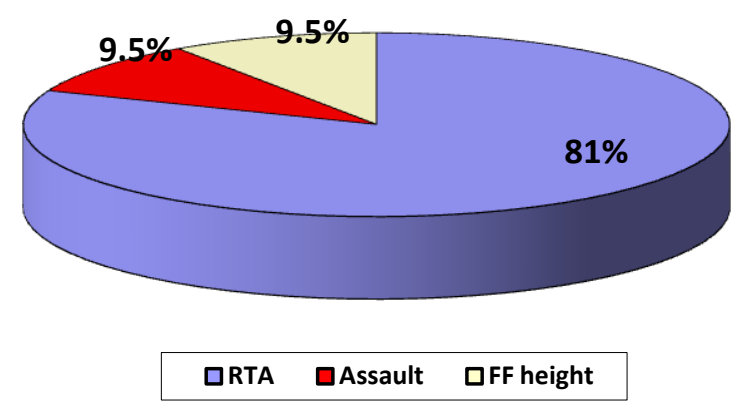

Fig. 3: Percentage distribution of the sample according to mode of injury

Table 4: Percentage distribution of the sample according to side

\begin{tabular}{|l|c|c|}
\hline Side & Number & Percent \\
\hline Right & 12 & $57 \%$ \\
\hline Left & 9 & $43 \%$ \\
\hline
\end{tabular}

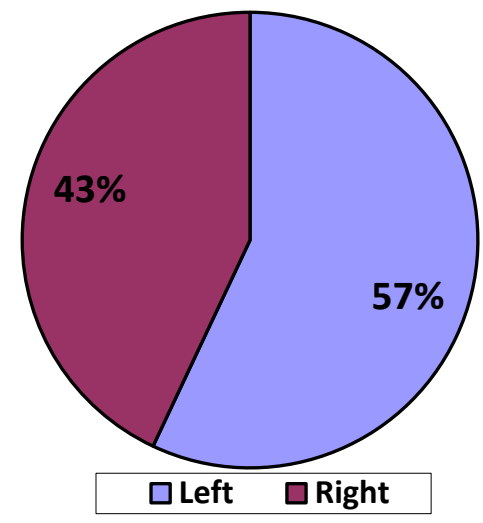

Fig 4: Percentage distribution of the sample according to side

Table 5: Percentage distribution of the sample according to AO/OTA type

\begin{tabular}{|l|c|c|}
\hline AO type & Number & Percent \\
\hline $\mathrm{A} 1$ & 10 & $47.61 \%$ \\
\hline $\mathrm{A} 2$ & 5 & $23.80 \%$ \\
\hline $\mathrm{A} 3$ & 2 & $9.52 \%$ \\
\hline $\mathrm{C} 1$ & 2 & $9.52 \%$ \\
\hline $\mathrm{C} 2$ & 2 & $9.52 \%$ \\
\hline
\end{tabular}

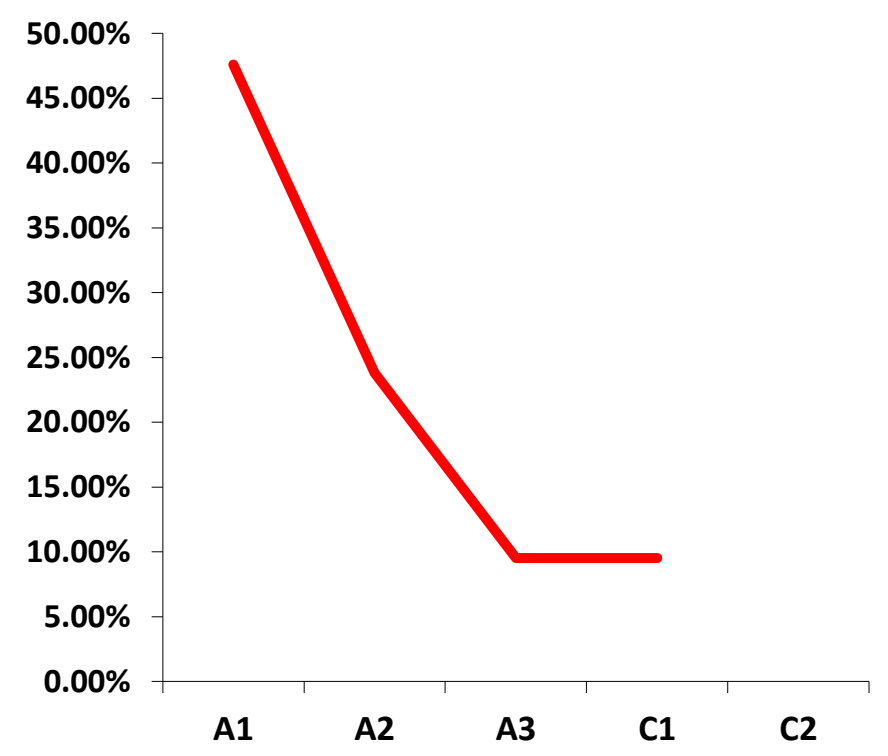

Fig 5: Percentage distribution of the sample according to AO/OTA type 


\section{Associated Injuries}

Table 6: Percentage distribution of the sample according to associated systemic injuries

\begin{tabular}{|c|c|c|c|}
\hline \multicolumn{2}{|c|}{ Associated systemic injuries } & Number & Percent \\
\hline \multirow{2}{*}{ Head injury } & No & 21 & $95.45 \%$ \\
\cline { 2 - 4 } & Yes & 1 & $4.76 \%$ \\
\hline $\begin{array}{c}\text { Abdominal } \\
\text { injury }\end{array}$ & No & 19 & $90.4 \%$ \\
\cline { 2 - 4 } & Yes & 2 & $9.52 \%$ \\
\hline Chest injury & No & 20 & $95.2 \%$ \\
\cline { 2 - 4 } & Yes & 1 & $4.76 \%$ \\
\hline
\end{tabular}

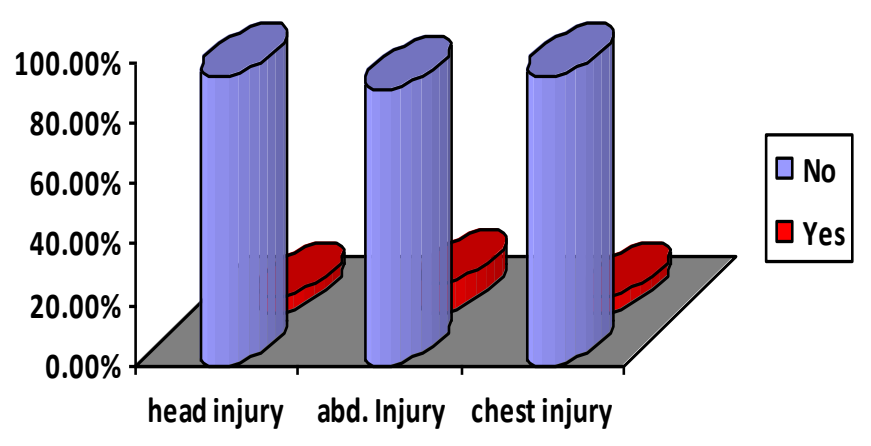

Fig. 6: Percentage distribution of the sample according to associated systemic injuries

Table 7: Percentage distribution of the sample according to associated bone and joint injuries

\begin{tabular}{|l|c|c|}
\hline & Number & Percent \\
\hline No injuries & 18 & $85.7 \%$ \\
\hline Lower limb & 1 & $4.76 \%$ \\
\hline Upper limb & 2 & $9.52 \%$ \\
\hline Spine & 0 & 0.0 \\
\hline Pelvis & 0 & 0.0 \\
\hline
\end{tabular}

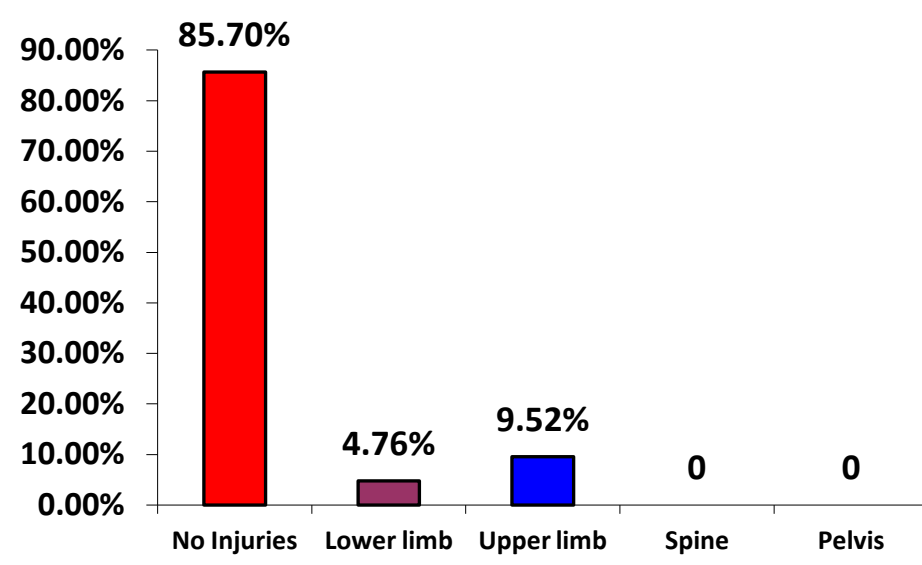

Fig.7 Percentage distribution of the sample according to associated bone and joint injuries

\section{Details Of Surgery}

Table 8: Percentage distribution of the sample according to immediate complication

\begin{tabular}{|l|c|c|}
\hline Immediate complication & Number & Percent \\
\hline None & 17 & $80.95 \%$ \\
\hline $\begin{array}{l}\text { Blood loss above } \\
1000 \mathrm{ml}\end{array}$ & 4 & $19.05 \%$ \\
\hline
\end{tabular}

\section{Analysis of Infection}

Table 9: Percentage distribution of the sample according infection

\begin{tabular}{|l|c|c|c|}
\hline Evaluation & Superficial & Deep & Organism \\
\hline Day 8 & $2(9.52 \%)$ & 0 & Enterobacter,Coliform \\
\hline Day 10 & $1(4.76 \%)$ & 0 & Pseudomonas \\
\hline 3 months & 0 & $1(4.76)$ & Mixed flora \\
\hline 6 months & 0 & $1(4.76)$ & MRSA \\
\hline
\end{tabular}

\section{Post- Operative Rehabilitations}

Table 10: Percentage distribution of the sample according to partial weight bearing

\begin{tabular}{|l|l|l|}
\hline Partial weight bearing & Number & Percent \\
\hline $6 \mathrm{Wks}$ & 2 & $9.52 \%$ \\
\hline $8 \mathrm{Wks}$ & 17 & $80.95 \%$ \\
\hline $10 \mathrm{Wks}$ & 2 & $9.52 \%$ \\
\hline
\end{tabular}

Table 11 Percentage distribution of the sample according to full weight bearing

\begin{tabular}{|l|c|c|}
\hline Full weight bearing & Number & Percent \\
\hline 4 months & 10 & $47.6 \%$ \\
\hline 6months & 6 & $28.56 \%$ \\
\hline 9 months & 5 & $23.8 \%$ \\
\hline
\end{tabular}

Table 12 Percentage distribution of the sample according to secondary procedures

\begin{tabular}{|l|c|c|}
\hline Secondary procedures & Number & Percent \\
\hline None & 19 & $90.47 \%$ \\
\hline Bone grafting & 1 & $4.76 \%$ \\
\hline Curettage & 1 & $4.76 \%$ \\
\hline
\end{tabular}

\section{Fracture Union And Complications}

Table 13: Percentage Distribution of sample according to fracture union

\begin{tabular}{|l|c|c|}
\hline Fracture union & Number & Percent \\
\hline Up to 4 months & 4 & $19.04 \%$ \\
\hline Up to 6 months & 14 & $66.66 \%$ \\
\hline Up to 9 Months & 21 & $100 \%$ \\
\hline
\end{tabular}


Table 14 Percentage distribution of the sample according to complication

\begin{tabular}{|l|c|c|}
\hline Complications & Number & Percent \\
\hline None & 9 & $42.85 \%$ \\
\hline Delayed Union & 2 & $9.52 \%$ \\
\hline Non Union & 1 & $4.76 \%$ \\
\hline Shortening & 3 & $14.28 \%$ \\
\hline Superficial infection & 3 & $14.28 \%$ \\
\hline Deep infection & 2 & $9.52 \%$ \\
\hline
\end{tabular}

\section{Functional Outcome}

Table 15: Percentage distribution of the sample according to thefunctional assessment based LEM score

\begin{tabular}{|c|c|c|}
\hline LEM score & Number & Percent \\
\hline $71-80$ & 2 & $9.5 \%$ \\
\hline $81-90$ & 14 & $66.6 \%$ \\
\hline $91-100$ & 5 & $23.8 \%$ \\
\hline
\end{tabular}

Table 16: Percentage distribution of the sample according to the functional evaluation based on Knee score

\begin{tabular}{|l|c|c|}
\hline Knee score & Number & Percent \\
\hline 36-40(Excellent) & 3 & $14.28 \%$ \\
\hline $26-35$ (Good) & 11 & $52.38 \%$ \\
\hline 16-25(Fair) & 5 & $23.80 \%$ \\
\hline $0-15$ (Poor) & 2 & $9.5 \%$ \\
\hline
\end{tabular}

\section{Discussion}

Surgical treatment of supracondylar fracture should provide rigid fixation for bone to unite early and adequate soft tissue coverage for the external wound healing. The locked compression plating (In this study we used the LISS plate, the LCP for limited invasive skeletal stabilisation system which can be used for open reduction and internal fixation also) provide the above satisfactorily.

Among the study subjects 38\% belonged to 20-39 years, $29 \%$ belonged to $40-59$ years and $33 \%$ were in the above 60 category. This finding correlates with the bimodal age distribution of supracondylar fracture femur. Males contribute to $62 \%$ and females $38 \%$. This epidemiological distributions are found to be comparable with the results published in various studies. ${ }^{13}$

Significantly, majority (81\%) sustained the fracture due to road traffic accidents. The rest being equally divided between fall from height and assault (9.5\% each).57\% of the study subjects had right sided supracondylar fracture. And majority of the study subjects had A1 (47.61\%) and A2 (23.80\%) type of fracture. Patients with simple fracture patterns tend to do well with surgical treatment, and more complex fractures (type C3) are associated with higher risk of complication and poor outcome. ${ }^{14}$

In this study I selected 22 patients initially but one patient was excluded for final evaluation because of head injury, since such patients take longer time for rehabilitation. There were two patients with abdominal injury and one with chest injury. Both were included because early rehabilitation was possible and the functional assessment could be done.

Among the cases majority were isolated supracondylar fracture. There was one case of bimalleolar fracture of the opposite lower limb; which was treated by Open Reduction and Internal Fixation (ORIF) and two cases of upper limb fractures; one distal end of radius and the other both bone fore arm fracture. These were treated by JESS and ORIF with DCP respectively.

Majority (80.95\%) had no immediate complication. 4(19.05\%), had blood loss above $1000 \mathrm{ml}$ and required blood transfusion.

There were 2 cases of delayed union. Out of which one was treated conservatively by further immobilisation for 6 weeks by knee brace and achieved union. The other case needed bone grafting at $7^{\text {th }}$ month and united in 7 weeks time. In my study there was no angulation or rotational malalignment as complication. This may be because the locking plates are fixed angle devices. The screws lock to the plate and therefore provide angular stability to the construct that conventional screws do not. For the distal femur, angular stability of the distal screws will help to prevent varus collapse. The locking screws may also provide stronger fixation of the plate in the proximal fragment by eliminating any potential for toggle and sequential screw loosening. This could have particular advantage on osteoporotic bone. $^{15}$ 
Among the subjects 3 had superficial infection within a 2 weeks period which was treated conservatively by culture and sensitivity. Only 2 had deep infection within in a 6 months period out of which one was treated conservatively and one case of deep infection with MRSA was treated by open debridement and curettage and which healed properly in 6 weeks time.

Among the study subjects 2(9.52\%) were advised partial weight bearing by 6 wks. And the rest, $17(80.95 \%)$ and $2(9.52 \%)$ were put on partial weight bearing 8 weeks and 10 weeks after surgery respectively. In this study most of patients start partial weight bearing by 2 months. This indicates that we can start early mobilization and rehabilitation by this mode of treatment. Mast et al. stressed that anatomic reduction of each articular fragment, absolute stability of the fixation, and early range of motion to minimise the risk of post traumatic arthritis. ${ }^{16}$

Majority (47.6\%) of the subjects achieved full weight bearing at 4 months and in five patients, the full weight bearing had to wait till 9 months after surgery.

In the study subjects only $2(9.52 \%)$ underwent secondary procedures, 1 to correct non union by bone grafting at $7^{\text {th }}$ month and the other underwent curettage for deep infection at 6 months.

With regard to fracture union, 4(19.04\%) had achieved the same by $4^{\text {th }}$ month, $14(66.66 \%)$ by 6 months. By 9 months all the study subjects had complete union. This result may be due to rich vascular supply of the distal metaphyseal region of the femur. Plate with locking screws function as internal fixator and have a possible biological advantage over conventional plates. The plate is not compressed against a cortex and therefore periosteal blood supply may be preserved.

Among the 21 participants in the study 5(23.8\%), $14(66.6 \%)$ and $2(9.5 \%)$ had LEM scores of 91$100,81-90$ and 71-80 respectively. The LEM score evaluate the daily activities of the patients. The above value suggest that majority of the patients in this study achieved a good range of score $(>81)$ by 6 to 9 months period. A recent long term follow up of type B and C distal femur fractures managed by open reduction and internal fixation recorded good to excellent results in $84 \%$ of cases. The mean knee range of motion was 118 degrees. Patients with isolated injuries had better outcome than those with multiple injuries. ${ }^{17}$

In functional evaluation based on Modified Knee Score, 3(14.28\%) had Excellent knee score, only 2(9.5\%) had Poor knee score. Among the rest majority (11) had Good Knee Score and 5 had Fair Knee Score. This scoring system was chosen because it emphasizes the most important patient outcome factors, pain and knee range of movement. Most of the patient had a good result after sustaining the fracture and returned to the same pre injury level of activity and range of motion. This range of motion was comparable with other studies like Giles et al. supracondylar fractures of the femur treated with plate and lag screw fixation. ${ }^{18}$

\section{Conclusion}

Supracondylar fractures of the distal femur historically have been difficult to treat. Most of these fractures tend to be comminuted and occur in elderly or multiply-injured patients. The incidence of complications like mal union, non union and infections are relatively high in these type of fractures.

In our institution these type of fractures are mostly treated by Open Reduction and internal Fixation (ORIF). Commonly used methods for internal fixation are Locked Compression Plating with LISS plate and Condylar Buttress Plate, Dynamic Condylar screw with side plate and closed retrograde intra medullary nailing.

The aim of this study was to assess the functional outcome of ORIF for supracondylar fracture femur with LISS plate. The activity of daily living was assessed by lower extremity measure score and the functional evaluation was based on modified knee score.

I selected 21 patients who underwent this procedure in Medical College Hospital 
Thiruvananthapuram during my study period. Majority of the study subjects were less than 60 years of age. Males constituted majority of the study subjects and Road traffic Accidents were found to be the major mode of injury.

After surgery three patients developed superficial infection within the first twoweeks and two developed deep infection within a 6 months period which were treated successfully. Most of the patients started partial weight bearing by 8 wks. In majority of patients full weight bearing was achieved by six months and all 21 of them started full weight bearing by 9 months.

In my study the functional outcome as measured by LEM score and Functional evaluation based on Modified Knee Score were comparable to other published studies. Among the 21 patients, 16 (76.19\%) had a LEM score of >81 and $14(66.6 \%)$ had good to excellent knee score.

There are various modalities of treatment available to manage supracondylar fracture femur. Conservative management carries the risk of prolonged immobilization, joint stiffness and malunion. It is now recognized by most Orthopaedic Surgeons that distal femoral fractures are best treated with reduction and surgical stabilization.

Open reduction and internal fixation with Locked Compression Plating offers anatomical reduction of the intraarticular fragments, stable and rigid fixation, better soft tissue and bone healing. The findings in my study reiterate the advantages of Open Reduction and Internal Fixation with Locked Compression Plating. With regard to functional outcome, this procedure offers good results to the young and elderly who sustain supracondylar fracture femur.

\section{References}

1. Moore et al., 1987. Moore TJ, Watson T, Green SA, et al: Complications of surgically treated supracondylar fractures of the femur. $J$ Trauma $1987 ; 27: 402.1$
2. Chapman and Henley, 1994. Chapman JR, Henley MB: Double plating of distal femur fractures: indications and techniques. Tech Orthop 1994; 9:210.

3. Marti A, Fankhauser C, Frenk A, et al. Biomechanical evaluation of the less invasive stabilization system for the internal fixation of distal femur fractures. J Orthop Trauma 2001;15:482â€"487.

4. Jazrawi et al., 2000. Jazrawi LM, Kummer FJ, Simon JA, et al: New technique for treatment of unstable distal femur fractures by locked double-plating: case report and biomechanical evaluation.

J Trauma 2000; 48:87.

5. Markmiller et al., 2004. Markmiller M, Konrad G, Südkamp N: Femur-LISS and distal femoral nail for fixation of distal femoral fractures: are there differences in outcome and complications. Clin Orthop Relat Res 2004; 426:252.

6. Kennedy JC. Complete dislocation of the knee joint. J Bone Joint Surg Am 1963;45;889-904.

7. Probe, 2003. Probe RA: Lower extremity angular malunion: evaluation and surgical correction. J Am Acad Orthop Surg 2003; 11:302.

8. Barquet et al., 1988. Barquet A, Silva R, Massaferro, et al: The AO tubular external fixator in the treatment of open fractures and infected non-unions of the shaft of the femur. Injury 1988; 19:415.

9. Firoozbakhsh et al., 1995. Firoozbakhsh K, Behzadi K, DeCoster TA,et al: Mechanics of retrograde nail versus plate fixation for supracondylar femur fractures. J Orthop Trauma 1995; 9:152. 10. Noyes et al., 1989. Noyes FR, Grood ES, Torzilli PA: The definitions of terms for motion and position of the knee and injuries of the ligaments. $J$ Bone Joint Surg 1989; 71A:465. 
11. Cain and Clancy, 2001. Cain EL, Clancy WG: Treatment algorithm for osteochondral injuries of the knee. Clin Sports Med 2001; 20:321.

12. Jaglal S, Lakhani Z, Schatzker J. "Reliability validity, and responsiveness of the Lower Extremity Measure for patients with a hip fracture". J Bone Joint Surg Am. 2000;82:955-962.

13. Acta orthopaedic Brussels, dept of orthopedics surgery and traumatology, vol. 64-4 2006.

14. Schatzker J. Fractures of the distal Femur revisited Clin Orthop Relat Res 1998; $347: 43 \& 56$.

15. Haiduukewych G.J. Innovations in locking plate technology. J Am Acad Orthop Surg 2004 12:205 and 212.

16. Mast J, Jakob R, Ganz R, Plannign and reduction techniques in fracture surgery, New York: Springer - Verlagi 1989.

17. Rademakers M.V., Kerkhofts GMMJ, Sierevelt IN, et al. Intraarticular fractures of the distal femur: A long germ follow-up study of surgically treated patients $J$ Orthop Truama 2004; 18: 213 \& 219.

18. Giles JB, DeLee JC, Heckman JD, Keever JE: Supracondylar-intercondylar fractures of the femur treated with a supracondylar plate and lag screw. JBone Joint Surg 64A:864-870. 